\title{
Parental and professional perception of need for emergency admission to hospital: prospective questionnaire based study
}

\author{
R MacFaul, M Stewart, U Werneke, J Taylor-Meek, H E Smith, I J Smith
}

\begin{abstract}
Aim-To compare views of parents, consultants, and general practitioners on severity of acute illness and need for admission, and to explore views on alternative services.
\end{abstract}

Method-Prospective questionnaire based study of 887 consecutive emergency paediatric admissions over two separate three week periods in summer and winter of five Yorkshire hospitals, combined with a further questionnaire on a subsample.

Outcome measures-Parental scores of need for admission and parent and consultant illness severity scores out of 10 . Consultant judgment of need for admission. Alternatives to admission considered by consultants and, for a subsample, by parents and family GP.

Results-Ninety nine per cent of parents thought admission was needed. Parents scored need for admission more highly than severity of illness with no association observed between severity and presenting problem or diagnosis. High parental need score was associated with a fit, past illness, and length of stay. Consultant illness severity scores were skewed to the lower range. Consultants considered admission necessary in $71 \%$, especially for children aged over 1 year, presentation with breathing difficulty or fit, and after a longer stay. More admissions in the evening were considered unnecessary as were admissions after longer preadmission illness, gastroenteritis, or upper respiratory tract infection. Of a subsample of parents, $81 \%$ preferred admission during the acute stage of illness even if home nursing had been available. Similar responses were obtained from GPs. Alternative services could have avoided admission for $19 \%$ of children, saving $15.6 \%$ of bed days used.

Conclusions-Medical professionals and parents differ in their views about admission for acute illnesses. More information is needed on children not admitted. Alternative services should take account of patterns of illness and should be acceptable to parents and professionals; cost savings may be marginal.

(Arch Dis Child 1998;79:213-218)

Keywords: emergency admission; parental views; health economics
The Court Report in 1976 recommended that "whenever the illness and circumstances allow a child will be cared for at home". ${ }^{1}$ Adhering to this recommendation one might have expected to see a downward trend in paediatric admissions. Instead, the subsequent period has been characterised by steadily rising admission rates from $21 / 1000$ children in 1975 to $51 / 1000$ in $1993 .^{2}$ The reasons for this increased use of inpatient paediatric resources are not well understood, and routinely collected data provide little understanding of the events surrounding admission. The discharge diagnosis is routinely recorded but does not reflect the clinical picture, parental concerns, social circumstances, or why hospital care was considered necessary. For example, an infant discharged with the apparently simple diagnosis of "a cold" may have been admitted because of suspicion of serious infection and required several investigations and a range of observations to exclude a diagnosis of meningitis or other significant illness. A paucity of information exists on the severity of illness and parental, general practitioner (GP), and consultant views about the need for admission. This study aimed to examine the severity of illnesses found in children admitted as paediatric emergencies and to assess the need for admission as judged by parents and the consultant in charge. It was part of a larger study to examine acute medical paediatric admissions and their appropriateness.

\section{Methods}

All emergency general paediatric admissions ( $n=887$ ) during two separate three week periods, one in summer and one in winter, were sampled in five hospitals in Yorkshire. Further details of the study design and medical and social characteristics of the study population are reported in an accompanying paper. ${ }^{3}$

Questionnaires were completed at admission by parent and admitting senior house officer and by consultant paediatrician after the child had left hospital. Demographic and clinical data collected included age, sex, postcode, time and route of admission, and nature and duration of presenting problem. Parents were asked to record their perception of the severity of their child's illness and need for admission on visual analogue scales of 0 to 10 . A score of 9 or more was arbitrarily considered to be a high score. After the child's discharge the consultant recorded overall severity of illness on a similar scale, and need for admission as a simple yes/no opinion. Consultants were also asked to record the reason why they felt admission was needed 


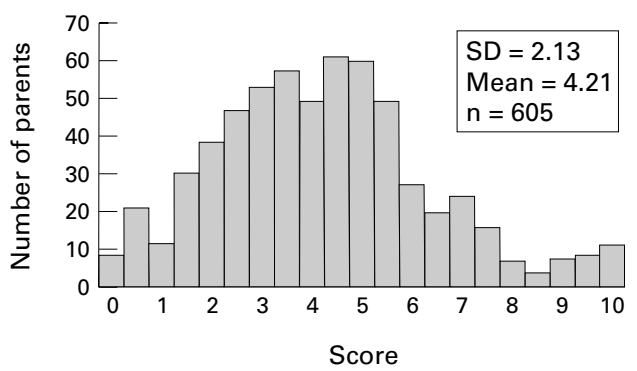

Figure 1 Parental score for severity of their child's illness at time of admission.

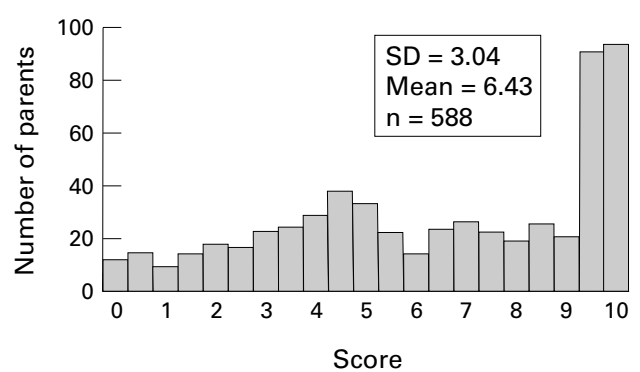

Figure 2 Parental score for need for admission.

and what alternative services, if available, might have prevented the admission.

For a randomly selected subsample of 123 admissions the views of parents and GPs on alternatives to admission were sought two weeks after discharge using a postal questionnaire. A series of questions requested answers on a visual analogue scale with a free text section inviting comments.

The data were described using frequency distributions. Spearman rank correlation and paired $t$ test were applied to analyse the relation between the scores given by the parents for severity of illness and need for admission. Factors influencing the consultant judgment on need for admission were examined using univariate and multivariate analysis, the procedures for which we have described previously. ${ }^{3}$

\section{Results}

There were 887 admissions during the study periods. The general characteristics of the sample are described in detail elsewhere. ${ }^{3}$ Data collections were incomplete to a variable extent in individual children. In summary, however, $64 \%$ were aged 3 years or under, with a median age of 1.9 years, $67 \%$ were admitted after referral by GP, and $32 \%$ after self referral to an accident and emergency department, $53 \%$ of admissions took place between 18:00 and 08:00. The most common presenting problems were breathing difficulty $(24 \%)$, fit $(16 \%)$, and

Table 1 Variables associated with high parental need score

\begin{tabular}{llllll}
\hline & \multicolumn{2}{l}{ Univariate analysis } & & \multicolumn{2}{l}{ Logistic regression } \\
\cline { 2 - 3 } \cline { 5 - 6 } \cline { 5 - 6 } & Odds ratio & $95 \% C I$ & & Odds ratio & $95 \% C I$ \\
\hline $\begin{array}{llllll}\text { Past illness } \\
\text { Presenting problem }\end{array}$ & $1.81^{\star}$ & 1.25 to 2.63 & & 1.53 & 0.99 to 2.36 \\
$\quad$ Fit & $2.19^{\star}$ & 1.41 to 3.39 & & $1.81^{\star}$ & 1.11 to 2.95 \\
Ingestion & $0.28^{\star}$ & 0.08 to 0.96 & & 0.55 & 0.29 to 1.23 \\
\hline
\end{tabular}

Logistic regression is adjusted for variables in univariate analysis $\mathrm{p}<0.1$ (age, Carstairs score, past illness, associated problem, presenting problem, and hospital). ${ }^{\star} \mathrm{p} \leqslant 0.05$. feverish illness (15\%); and the most frequent discharge diagnoses were upper respiratory tract infection (15\%), gastroenteritis $(10 \%)$, febrile convulsion ( $8 \%$ ), and asthma $(8 \%)$. Stay in hospital was $<24$ hours in $24 \%$ of children and $61 \%$ spent one night or less in hospital.

PARENTAL VIEWS ON NEED FOR ADMISSION AND ILLNESS SEVERITY.

A total of $605(68 \%)$ parents completed the section on illness severity and $588(66 \%)$ on need for admission. Missing data were distributed without significance across the hospitals and diagnoses. Parental assessment of the severity of their child's illness showed a mean (SD) score of 4.2 (2.1) (fig 1). There was no relation between severity score and presenting problem, diagnosis, socioeconomic status, or other factors. In contrast with the normal distribution of severity of illness scores, the parental need for admission scores were highly skewed to the left, with one third (198/588) of the parents scoring 9 or above (fig 2). A total of $29(5 \%)$ gave a need score of $<1$ but only two parents thought there was no need for admission.

A fit and parental recall of past illness were associated with a high parental need for admission score while admissions after ingestion of potentially toxic substances were not (table 1). There was no association between parental need score and age of child, time or route of admission (GP or self referral to accident and emergency department), or socioeconomic status. High need score was positively associated with a length of stay $>24$ hours (OR 1.77; $95 \%$ CI 1.11 to $2.84 ; \mathrm{p}<0.05)$. Severity of illness and need for admission were only moderately correlated $(r=0.31)$, and parents scored need for admission significantly higher than severity of illness $(p<0.001)$. When parental illness severity score was introduced into the model as a continuous (unfactored) variable, it remained the only significant variable.

\section{CONSULTANTS VIEWS ON NEED AND SEVERITY}

SCORE

Binary (yes/no) judgments were available for $695(78 \%)$ admissions. Consultants considered that admission was necessary in 491 $(71 \%)$ of these children. In 447 children $(64 \%)$ this was for inpatient observation, investigation, or treatment facilities. In 17 children (2\%) an admission was necessitated by the lack of appropriate outpatient or community facilities, and in 12 children (2\%) admission was required because of social factors alone. A diagnosis of asthma or lower respiratory tract infection, low socioeconomic status, or admission after self referral to accident and emergency department, were positively related to need for admission. However, these factors did not remain significant in multivariate analysis (table 2). This showed significant increased need in children $>1$ year old, length of stay $>24$ hours, and presentation with breathing difficulty or fit. Less likely to be needed were admission in the evening, preadmission illness $>24$ hours, and discharge diagnosis of 
Table 2 Medical and sociodemographic variables associated with need for admission as judged by consultants $(n=695)$

\begin{tabular}{|c|c|c|c|c|c|}
\hline & \multirow{2}{*}{$\begin{array}{l}\text { fudged needed } \\
(\%)\end{array}$} & \multicolumn{2}{|c|}{ Univariate analysis } & \multicolumn{2}{|c|}{ Logistic regression } \\
\hline & & Odds ratio & $95 \% C I$ & Odds ratio & $95 \% C I$ \\
\hline \multicolumn{6}{|l|}{ Age } \\
\hline$\leqslant 1$ year & 62 & Baseline & & Baseline & \\
\hline$>1$ year and $\leqslant 3$ years & 72 & $1.60^{\star}$ & 1.07 to 2.38 & $2.42^{\star}$ & 1.22 to 4.81 \\
\hline$>3$ years & 80 & $2.43 \dagger$ & 1.62 to 3.65 & $2.72 \dagger$ & 1.38 to 5.37 \\
\hline \multicolumn{6}{|l|}{ Admission time } \\
\hline Day & 89 & Baseline & & Baseline & \\
\hline Evening & 64 & $0.62^{\star}$ & 0.42 to 0.93 & $0.54 \ddagger$ & 0.29 to 1.00 \\
\hline Night & 72 & 0.91 & 0.58 to 1.42 & 1.33 & 0.62 to 0.87 \\
\hline \multicolumn{6}{|l|}{ Length of stay } \\
\hline$\leqslant 24$ hours & 56 & Baseline & & Baseline & \\
\hline$>24$ hours & 75 & $2.37 \dagger$ & 1.64 to 3.42 & $7.62 \dagger$ & 3.76 to 15.46 \\
\hline \multicolumn{6}{|l|}{ Time ill before presentation } \\
\hline$\leqslant 6$ hours & 82 & Baseline & & Baseline & \\
\hline$>6$ hours and $\leqslant 24$ hours & 81 & 0.94 & 0.51 to 1.73 & 1.17 & 0.44 to 3.12 \\
\hline$>24$ hours & 62 & $0.36 \dagger$ & 0.23 to 0.56 & $0.49^{\star}$ & 0.25 to 0.98 \\
\hline \multicolumn{6}{|l|}{ Presenting problem } \\
\hline Breathing difficulty & 80 & $1.91 \dagger$ & 1.25 to 2.94 & $2.81 \dagger$ & 1.39 to 5.66 \\
\hline Fit & 88 & $3.81 \dagger$ & 2.13 to 6.84 & $5.07 \dagger$ & 1.96 to 13.07 \\
\hline \multicolumn{6}{|l|}{ Discharge diagnosis } \\
\hline URTI & 45 & $0.27 \dagger$ & 0.18 to 0.41 & $0.21 \dagger$ & 0.10 to 0.44 \\
\hline Gastroenteritis & 47 & $0.33 t$ & 0.20 to 0.53 & $0.44^{\star}$ & 0.20 to 0.97 \\
\hline Gut disorder & 58 & 0.56 & 0.28 to 1.12 & $0.32^{\star}$ & 0.11 to 0.94 \\
\hline
\end{tabular}

Logistic regression is adjusted for variables on which information was available at discharge with $\mathrm{p}<0.1$ in univariate analysis. ${ }^{*} \mathrm{p}<0.05 ; \mathrm{p} \leqslant 0.01 ; \neq \mathrm{p}=0.05$.

URTI, upper respiratory tract infection.

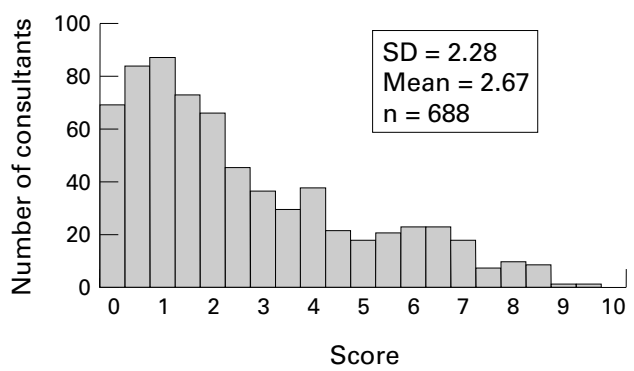

Figure 3 Consultant score for severity of illness during admission.

gastroenteritis, upper respiratory tract infection, or gut disorder (which included gastrooesophageal reflux, unspecified vomiting, chronic diarrhoea, and failure to thrive).

Consultant severity of illness scores out of 10 were skewed to the right with a mean score of 2.6 , a median score of 1.9 , and only $10 \%$ of scores exceeded 6 (fig 3). Consultant assessment of need for admission was related to their assessment of severity, with a mean (SD) severity score of 2.9 (2.37) when admission was needed and 1.1 (0.93) when not $(\mathrm{p}<0.0001)$. There were no differences among hospitals for the consultant need ratings according to diagnosis, age, and length of stay.

\section{ALTERNATIVE ARRANGEMENTS FOR CARE}

Parental views

Sixty eight $(55 \%)$ of the 123 parents contacted after discharge responded to the postal questionnaire. The response rate from parents who

Table 3 Parental responses to alternative models of care

\begin{tabular}{|c|c|c|c|}
\hline Models of care & $\begin{array}{l}\text { GP admission } \\
(n=54)\end{array}$ & $\begin{array}{l}\text { A\& E admission } \\
(n=14)\end{array}$ & $\begin{array}{l}\text { Total } \\
(n=68)\end{array}$ \\
\hline Admission necessary & $80 \%$ & $86 \%$ & $81 \%$ \\
\hline $\begin{array}{l}\text { Would have been happy to take child home } \\
\text { after been seen at hospital }\end{array}$ & $11 \%$ & $0 \%$ & $9 \%$ \\
\hline $\begin{array}{l}\text { Prefer to care for child at home with nursing } \\
\text { or other help }\end{array}$ & $15 \%$ & $0 \%$ & $12 \%$ \\
\hline $\begin{array}{l}\text { Prefer to care for child at home with nursing } \\
\text { or other help after acute period passed }\end{array}$ & $48 \%$ & $71 \%$ & $53 \%$ \\
\hline
\end{tabular}

Categories were not mutually exclusive. had self referred to an accident and emergency department ( 14 out of $33 ; 39 \%$ ) was lower than from parents whose GP had made the referral to hospital ( 54 out of $90 ; 60 \%$ ). In response to suggestions about possible alternatives to admission, such as home nursing care for the child, $81 \%$ felt admission would still be needed and $88 \%$ expressed a preference for their child to be in hospital until the acute stage of the illness had passed (table 3 ). Parents views about admission were expressed in $51(75 \%)$ of returned questionnaires and a selection are shown (box). Negative comments were made in only four instances and related to accommodation in two, and the need for admission was questioned in one child with diabetes and another with recurrent asthma.

\section{GP views}

A total of 106 (86\%) of the 123 GPs contacted by postal questionnaire responded. The responses included 28 of the $33(85 \%)$ admissions after self referral via an accident and emergency department and 78 of the $90(87 \%)$ after GP admission. The GPs judged $88 \%$ of admissions to be necessary. Additional services such as children's nurses calling into the home were not considered to be helpful to the GP and most preferred the child to be in hospital during the acute phase of the illness (table 4).

\section{Consultant responses}

For all admissions the consultant was asked after patient discharge what alternative services might have prevented the admission (table 5). Consultants suggested that alternative specialist services such as outreach or day case provision could have prevented admission in $19 \%$ of children. For the 689 admissions for whom information was available a total of 1985 bed days were used. If the alternative services suggested had been available locally and all $19 \%$ of admissions could have been avoided, it would have resulted in a saving of 309 bed days $(15.6 \%)$. 
Table 4 Responses to questionnaire sent to general practitioners $(n=78)$

\begin{tabular}{|c|c|c|c|}
\hline Question & $\begin{array}{l}\text { Admitted } \\
\text { via }\end{array}$ & Total & Yes $(\%)$ \\
\hline \multirow[t]{2}{*}{ Do you feel child's admission was necessary? } & $\mathrm{A} \& \mathrm{E}$ & $20 / 28$ & 71.4 \\
\hline & GP & $63 / 66$ & 95.5 \\
\hline \multirow{2}{*}{$\begin{array}{l}\text { If preventable admission, would you have preferred to care for } \\
\text { child at home with-for example, children's nurse visiting } \\
\text { during acute period? }\end{array}$} & $\mathrm{A} \& \mathrm{E}$ & $8 / 28$ & 28.6 \\
\hline & GP & $13 / 78$ & 16.7 \\
\hline \multirow{2}{*}{$\begin{array}{l}\text { If preventable admission, would you have preferred to care for } \\
\text { child at home with-for example, children's nurse visiting } \\
\text { after acute period? }\end{array}$} & $\mathrm{A} \& \mathrm{E}$ & $7 / 28$ & 25.0 \\
\hline & GP & $33 / 78$ & 42.3 \\
\hline
\end{tabular}

Sample size varies with differing numbers of responses to individual questions.

Table 5 Consultant views on alternative services that might have prevented admission

\begin{tabular}{lll}
\hline Service provision & Level & $\begin{array}{l}\text { Admissions } \\
(n=689)(\%)\end{array}$ \\
\hline A\&E facility & Primary & $4(0.6)$ \\
General practitioner & Primary & $77(11.2)$ \\
Social service & Primary & $10(1.5)$ \\
Health visitor & Primary & $1(0.2)$ \\
All primary care & & $92(13.5)$ \\
Outpatient or day case facility & Secondary & $77(11.2)^{\star}$ \\
Outreach & Secondary & $46(6.7)$ \\
Community paediatrician & Secondary & $2(0.3)$ \\
All secondary care & & $125(18.2)$ \\
Total & & $217(31.7)$ \\
\hline
\end{tabular}

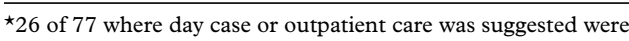
admitted at night.

\section{Discussion}

Most children had mild illnesses, were admitted for short periods of time, and required observation rather than treatment. Despite this, most acute medical admissions were felt to be necessary both by parents at the time of admission and by the consultant at discharge. Additional data collected two weeks after discharge from a sample of GPs and parents confirmed that a period of inpatient care was the preferred management in those who responded. These views were expressed without experience of alternative services, but they need to be considered when proposing and studying alternatives to admission.

Consultant subjective (implicit) judgment of need for admission was made after discharge and is influenced by benefit of hindsight. Seventy one per cent of admissions were judged to be necessary even though illnesses were usually not severe, which suggests factors other than illness severity influenced the opinion. Consultants perceived need for admission was greater in children presenting with a fit or breathing difficulty. Presenting problem outweighed the discharge diagnosis although both were closely related. Recognition of uncertainty of outcome at the time of presentation in acute illness is a more important predictor of need for admission. Thus data on presenting complaints, as well as discharge diagnosis, should routinely be recorded. ${ }^{3}$ Studies are needed on consultant opinion of need for admission at the time of presentation.

Consultants view on need for admission was rated equally frequently whether a child was admitted after GP referral or after self referral to an accident and emergency department. Length of stay was longer when parents had judged need for admission to be high. Both observations suggest that parent assessment of

\section{Examples of parental perceived benefits of admission}

- I was very pleased she was kept in overnight to be kept an eye on. Although she was not seriously ill, it put my mind at rest

- The admission was as unstressful as it was possible to be, particularly because I was able to stay the night with $\mathrm{X}$. The staff made every effort to make things easier, particularly in the accident and emergency and the $x$ ray departments

- We felt much happier about our son's condition when all the investigations had been done in hospital and would have been happy to take him home then, but were accepting of their advice to admit him

- Both myself and my daughter managed a decent night's sleep which we had not had for a couple of days. Just one night in hospital and $\mathrm{P}$ was a lot better

- I thought my son's admission to hospital was necessary not only for him but also for myself. It stopped me from panicking as I knew help was just outside the door. When I calmed down the doctors knew I wanted to go home and let me, so I needed no extra help because I was reassured that he was fine and just needed an eye kept on him

- I was frightened at home, but felt very secure in hospital with her being constantly monitored. I was allowed home as soon as I requested, which was as soon as I felt able to cope with her condition

- I felt that the nurses had more experience of a temperature that wouldn't drop because of convulsion. She also wasn't drinking or eating. Once her temperature dropped she started to eat and drink. This made us all happier

need for hospital attention is at least as valid as that of the GP although we do not know what proportion of accident and emergency attenders were not admitted compared with GP consultations - an aspect that requires further study. Peak time for admissions was in the evening and although, apart from breathing difficulty, the nature of illnesses did not differ in the evening, they were less likely to be judged as necessary by consultants. These findings suggest that doctors lower their threshold for admission in the evening and at night. Admission was also less likely to be considered necessary for gastroenteritis, upper respiratory tract infection, and gut disorders, and for illnesses of longer duration before admission. ${ }^{5}$ Provision of evening assessment and same day paediatric consultation clinics supported by outreach paediatric nursing, preferably as a 24 hour service, could potentially reduce admission for these children and for those with chronic disorders, present in $13 \%$ of our study population. ${ }^{36}$ Consultant 
judgment of need did not differ among hospitals for diagnosis, age, and length of stay suggesting professional agreement about how illnesses should be managed.

Parental measures of need for admission were not related to the age of the child and were only weakly associated with consultant opinion. Consultants judged need less in babies < 12 months. Parents rated illness severity higher than consultants and viewed admission as necessary even for illnesses they judged to be not so severe, although severity was the single most important factor influencing their perception of need for admission. Our study is limited by lack of qualitative data on parental perceptions. Further studies in acutely ill children, including those not admitted to hospital, are needed to understand how they influence decisions to admit. ${ }^{78}$ The data were collected at the time of admission when parents could be expected to be at their most concerned. However, results were similar from the responders to the questionnaire sent to a small subsample two weeks after admission.

In multivariate analysis, fit as a presenting problem and parental record of previous serious illness were found to influence parental perception of need for admission. Other studies have identified a fit in their child as an extremely frightening experience for parents-a view appreciated by consultants. ${ }^{9}$ Guidelines for referral and management of fit need to take these experiences into account. On the other hand, ingestion - a condition with potentially severe or even fatal consequenceswas inversely associated with high parental need score, suggesting that effective health education is lacking in this area. Parents and consultants record and perception of previous serious illness differed, and the way in which one illness is managed may influence how parents perceive and respond to subsequent illness with hospital care possibly leading to repeated "use". ${ }^{10}$

For acutely ill children, hospitals should provide a level of care for children and their families that cannot safely be delivered at home. The aim of many ambulatory or outreach services is to avoid overnight inpatient admission. Our findings emphasise the need for clear evidence that this approach is desirable, safe, and acceptable for children with acute illnesses. Parents views in the sample showed that they valued close observation by hospital staff (especially at night), access to investigations, or a period of respite (box). Improved "out of hours facilities", appear to be needed with resources at a comparable level, if not greater, than those in place during the day. The views of GPs were aligned with those of parents and they did not perceive a need for nursing care at home during the peak of the illness although this type of service has been found to be helpful for selected problems. ${ }^{11}$ However, neither parents nor GPs had experience of a home nursing service. Care delivered in the home is likely to be expensive. Resources released by a reduction in a few beds are unlikely to meet the costs. In
Australia, a children's emergency observation annexe led to a reduction of inpatient bed days. ${ }^{12}$ Although no detail was given, significant financial savings were implied and similar results were reported from a development in York. ${ }^{13}$ Alternatives to admission may not be practical. In our study consultants proposed outpatient or day case provision as an alternative for 77 children but these would not have been applicable to the one third of them who presented at night. Even if admission had been avoided for all 77 children, at most $15.5 \%$ of bed days would have been saved.

Possible detrimental effects of a short term hospital admission must be taken into account. These include risk of cross infection and upset to child and parent resulting from painful and possibly unnecessary procedures. These must be balanced against the cost to the parent of care at home in terms of anxiety (especially out of hours) and potential adverse clinical outcome. Although studies in the 1960s found that a hospital stay could have adverse psychological and behavioural effects on children and their families, ${ }^{14}$ there is little recent evidence. Improved conditions within hospitals with greater involvement of the parents, availability of children's wards, and specialist staff are likely to have minimised the negative psychological impact of admission to hospital. Contemporary studies of effects of admission are required. Increasing demand for admission from parents and GPs and the positive views expressed by them in this study imply that admission is an acceptable and welcome solution to acute illness in some children. Our efforts should be directed to refining the indications for admission for common disorders and, when inpatient care proves necessary, making the admission as easy, stress free, and short as possible.

Our results provide some insight into views of parents, GPs, and consultant paediatricians on the necessity and severity of paediatric medical emergency admissions. Though not entirely congruent with each other, there are many similarities. Our findings have significant implications for future development of paediatric services, which should take account of the views and needs of parents. This study was funded by the Department of Health. We express
our thanks to the consultants and the staff of the paediatric departments in Grimsby, Harrogate, Huddersfield, Hull, and Leeds General Infirmary for all their work in completion of this Leeds General Infirmary for all their work in completion of this
study. We also thank Dr T Cole for his statistical advice and Ptudy. We also thank Dr T Cole for his statistical advice an
Professor P Pharoah for his work on the steering committee.

1 Committee on child health services. Court report. Fit for the future. London: HMSO, 1976.

2 Department of Health. Health service indicators. London: DoH, 1993-4.

3 Stewart M, Werneke U, Taylor-Meek J, Smith HE, Smith IJ, MacFaul R. Medical and social factors involved in the admission and discharge of acutely ill children. Arch Dis
Child 1998;79:000-000.

Werneke U, Smith HE, Taylor J, Smith IJ, MacFaul R. Validation of the paediatric appropriateness evaluation proto
col in British practice. Arch Dis Child 1997;77:294-9.

5 Prince M, Worth C. A study of inappropriate attendances to a paediatric accident and emergency department. $\mathcal{F}$ Public Health Med 1992;14:177-82.

6 Cramp C. Commentary in ambulatory paediatrics-making a difference. Arch Dis Child 1997;76:468-76. 
7 Kai J. What worries parents when their pre school children are acutely ill, and why: a qualitative study. BMF 1996;313: are acu

8 Roberts H. Listen to parents. BMF 1996;313:954--5.

9 Baumer JH, David TJ, Valentine SJ, Roberts JE, Hughes BR. Many parents think their child is dying when having a first febrile convulsion. Dev Med Child Neur 1981;23:462-

10 McConnochie KM, Roghmann KJ, Kitzman HJ, Liptak GS, McBride JT. Ensuring high quality alternatives while ending paediatric in-patient care as we know it. Arch Pediatr Adolesc Med 1997;151:341-9.
11 Meates M. Ambulatory paediatrics-making a difference. Arch Dis Child 1997;76:468-76.

12 Browne GJ, Penna A. Short stay facilities: the future of efficient paediatric emergency services. Arch Dis Child cient paediatric

13 Beverley DW, Ball RJ, Smith RA, et al. Planning for the future: the experience of implementing a children's day assessment unit in a district general hospital. Arch Dis Child 1997;77:287-93.

14 Haslum MN. Length of preschool hospitalisation, multiple admissions and later educational attainment and behaviour. Child Care Health Dev 1988;14:275-91. 